\title{
Preaching to the converted
}

$\mathrm{I}^{\mathrm{n}}$ n October, I presented a summary of the Global Initiative Ifor Chronic Obstructive Lung Disease (GOLD) guidelines (1) at the Montreal meeting of the International Union Against Tuberculosis and Lung Diseases (IUATLD). The IUATLD has a third world orientation appropriate for an organization that has tuberculosis as a major concern. After my presentation, the GOLD guidelines were discussed, often in scathing terms, as being inappropriate for most of the world. GOLD recommended expensive therapies that are beyond the reach of most of the world's health care systems, and some discussants implied that GOLD was a self-promoting exercise by major pharmaceutical companies. I was tangentially involved in generating the GOLD guidelines and do not believe the latter charge; the people who wrote the guidelines are independent operators, and the product is little different from guidelines produced by various national thoracic societies. On the other hand, I cannot argue against the view that the GOLD guidelines were written by Western Europeans and North Americans, and probably can be best applied only in those territories. The orientation of GOLD is in part because little is known about the nature and prevalence of chronic obstructive pulmonary disease (COPD) in the third world, though predictions indicate that it will become a major problem as third world smoking continues to increase.

In any event, I came away from the meeting mildly surprised that the objections to the GOLD guidelines were so vehement; discussants obviously thought that the guidelines mattered. I was not so sure, and the paper by Boulet et al (pages 417 to 423) in this issue tends to support my skepticism. Boulet et al surveyed a large group of asthmatics and their physicians as to whether the patients' asthma control was satisfactory and as to the evidence used by the physicians in making this judgment. In short, they found that both patients and physicians overestimated the degree of control achieved compared with the Canadian asthma guidelines, and that the methods for assessing control varied considerably and seldom included measurements of expiratory flow. Interestingly, the patients overestimated their degree of asthma control more than did their doctors, but this is an issue for another editorial; what I am concerned about here is physician behaviour. Boulet et al are not the first authors to show that general compliance with asthma guidelines is poor among North American physicians (2), and several North American studies cited by Boulet et al, and one of our own (3), have shown that spirometry, the gold standard for the diagnosis and management of obstructive diseases, is

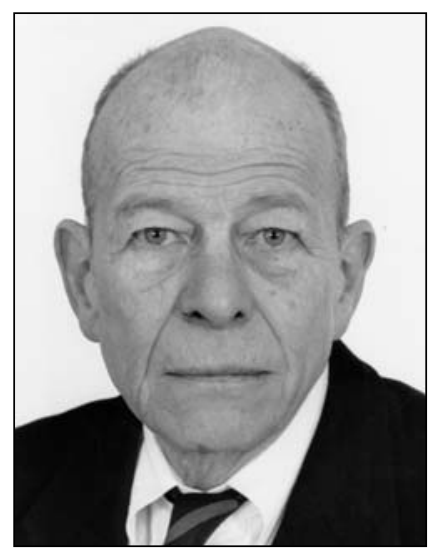

Nick R Anthonisen greatly underutilized.

Should we conclude that guidelines, at least for asthma and COPD, are documents by specialists, for specialists and about specialist practice? Are we guideline writers preaching to the converted? Though it is not our intent, it appears that that is what we are doing. Boulet et al and others (2) argue that the failure is one of communication, and that we should work harder at disseminating the guidelines, and it is hard to disagree with them. It is much easier, and more fun, to write guidelines than to convince general practitioners and family physicians to use them. There is evidence that continuing medical education can change physician behaviour (4), but the same paper indicates that the mere dissemination of written guidelines does not do so, that clinical management and counselling are the most difficult aspects of physician activities to change, and that the more intensive the educational effort, the more likely it is to work. These caveats are not reassuring.

As implied above, guideline writers are almost always specialists who may not appreciate the world of primary care physicians. The latter receive blizzards of guidelines dealing with everything from gall bladder disease to the management of pregnancy. Apparently, they apply some but not others. If guidelines instruct them about therapies that could be regarded as futile, as in COPD, or ask for them to do things that make them uncomfortable and for 
which they don't get paid, as in spirometry, then they are likely to have little impact. Perhaps we should rethink our guidelines.

In any event, I am very happy that I will not be introducing the GOLD guidelines to the third world.

\section{Nick R Anthonisen MD} Editor-in-Chief Canadian Respiratory Journal

\section{REFERENCES}

1. Pauwels RA, Buist S, Calverly PMA, Jenkins CR, Hurd SZ. Global strategy for the diagnosis, management, and prevention of chronic obstructive pulmonary disease. Am J Respir Crit Care Med 2001;163:1256-76.

2. Doerschug KC, Peterson MW, Dayton CS, Kline JN. Asthma guidelines and assessment of physician understanding and practice. Am J Respir Crit Care Med 1999;159:1735-41.

3. Anthonisen NR, Dik N, Manfreda J, Roos LL. Spirometry and obstructive lung disease in Manitoba. Can Respir J 2001;8:421-6.

4. Davis DA, Thomson MA, Oxman AD, Hayes RB. Evidence for the effectiveness of CME. JAMA 1992;268:1111-7. 


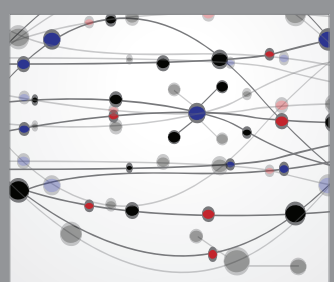

The Scientific World Journal
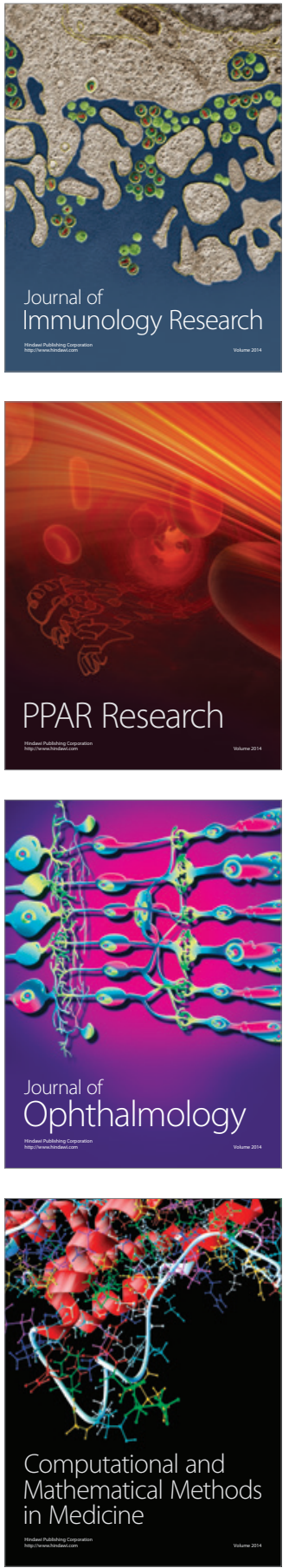

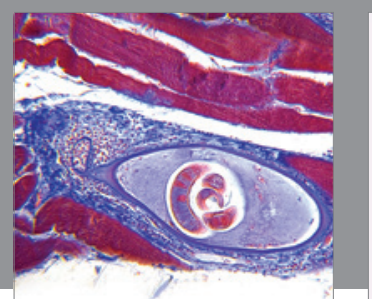

Gastroenterology Research and Practice

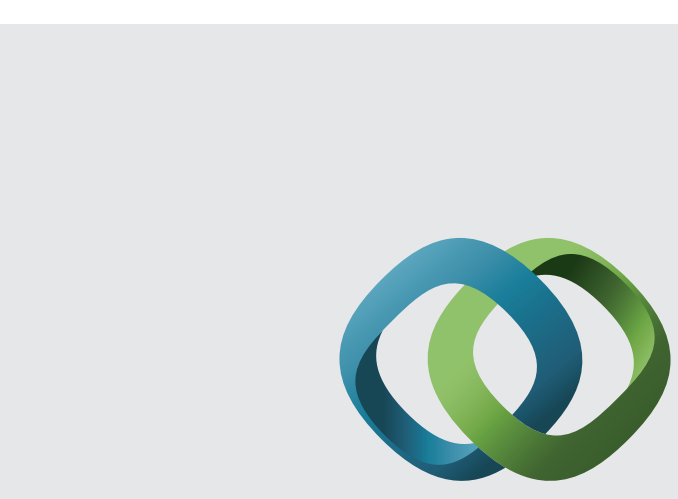

\section{Hindawi}

Submit your manuscripts at

http://www.hindawi.com
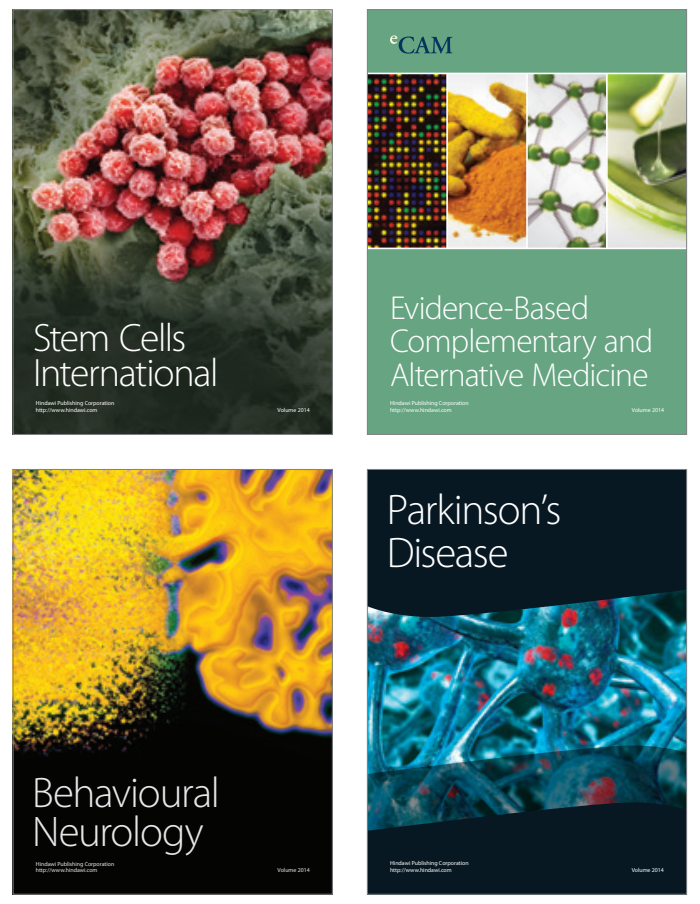
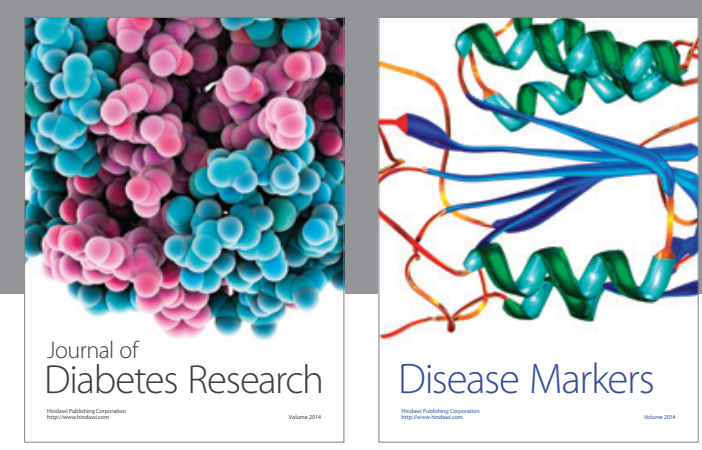

Disease Markers
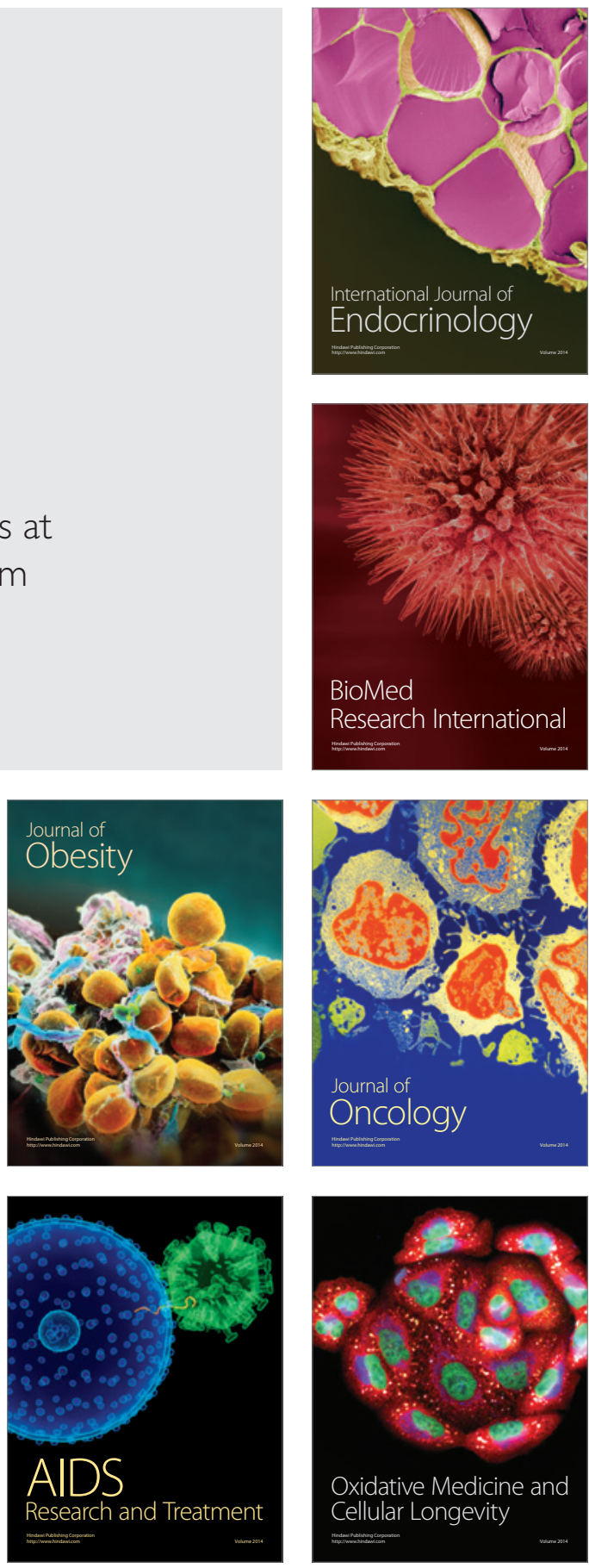